\title{
ChemEnterprise SLP
}

\begin{abstract}
Summary
A structured learning package (SLP) aimed at advanced undergraduate chemists featuring group problem solving and introducing the role of enterprise in a chemical industry business environment. The exercise is based on a real scenario and uses real data to provide opportunities to explore a number of alternative strategies and to communicate conclusions in oral and written report formats.
\end{abstract}

Subject Area: Chemistry

\section{Description}

Student teams represent a chemical company reacting to new, more stringent environmental legislation. They must research a number of end-of-pipe technologies and choose one based on actual cost and performance data. More significantly, they can turn the effluent problem into a new opportunity for their company with wider consequences for their business strategy.

\section{Type of activity}

The two-stage activity is paper-based with all materials available from the authors. This includes student handouts, full tutor's notes (with important recommendations on the administration of the exercise and discussion of typical student responses), sample handouts, overheads, and assessment schemes. The majority of up to 40 hours of student work are spent away from the classroom in independent group work.

Classroom sessions are used to introduce the exercise with two subsequent plenaries allowing teams to present their findings and conclusions. Each team gives two talks and delivers two written reports with peer and tutor feedback in between. These form the basis of the assessment of the exercise. The second report is essentially a business plan evaluating two potential future scenarios for the company business, and applying a number of business appraisal techniques and models to these.

\section{Content covered}

The effluent stream emerges from a plant producing optical brighteners. Students describe the photochemistry and synthesis of these materials involving various aspects of aromatic chemistry and reactivity. Existing and proposed alternative production routes can be analysed from the perspective of green chemistry.

Various processes in industrial effluent treatment are reviewed and applied such as adsorption, oxidation, ozonation, and electrochemical techniques. Each team in a class is assigned a technology to review. This requires students to find, apply, and present relevant information.

There is a large component of data analysis. This is real data as provided through a number of feasibility studies. Account must also be taken of legal and technical aspects of waste-water management by water boards and the Environment Agency. 
Both stages provide opportunities to apply creative solutions to an apparently straightforward problem. This provides opportunities to review the nature of problems and solutions, in general, and discuss the role of enterprise thinking in responding to, and driving, change within a chemical industry business environment.

Appraising new strategies provides experience of applying standard business environment and market models, and dealing with financial implications through discounted cash flow analysis.

\section{Application}

We have developed this exercise specifically for $3^{\text {rd }}$ year undergraduates on our 'Chemistry, Management, and Industry' course. They are familiar with the models and accounting principles used in project appraisal that are key elements of the second stage of ChemEnterprise SLP. The first stage requires no such background and could be tackled satisfactorily by chemists, engineers, environmental scientists etc. Many chemistry courses will include some students who have taken management and business options. Just one student with this background in each team should allow the second stage to run smoothly. Furthermore, the tutor's notes provide guidance on sources that can be used to introduce the management models and techniques useful in the second stage so that even this prerequisite can be circumvented.

Students tackle the structured learning package (SLP) over a period of 3-4 weeks concurrently with other courses. It can be thought of as replacing labwork over this period. There are opportunities, and we provide some suggestions in the tutor's notes, on how the SLP might be compressed into more of a classroom-based exercise.

\section{Further comments}

Our use of the SLP is to provide a high quality experience in which our students can apply, develop, and receive peer and tutor feedback on their personal transferable skills in a realistic chemistry context. Student performance is assessed on this basis. ChemEnterprise SLP also encourages participants to recognise the concept of enterprise in solving technical problems in a commercial environment. We do not fully exploit the opportunities provided to learn chemistry, industrial chemistry and engineering, and aspects of environmental science though clearly the emphasis could be changed to bring these to the fore.

\section{Author(s)}

Brian Grievson, Nigel Lowe and Alan Rose

\section{Contact details}

Nigel Lowe (and Brian Grievson)

Department of Chemistry, University of York, Heslington, York, YO10 5DD nl6@york.ac.uk

Alan Rose

Hickson \& Welch Ltd, Wheldon Road, Castleford, W. Yorkshire, WF10 2JT.

\section{Reference}

Proceedings, Variety in Chemistry Teaching 2002, University of Keele, Sept 2002 